\title{
IMPACTOS SOCIOAMBIENTAIS À MARGEM DO RIO SÃO FRANCISCO: RESULTADO DA FALTA DE CONSIDERAÇÃO DA ÁREA DE INFLUÊNCIA REAL
}

\author{
Regnaldo Gouveia dos Santos*
}

\section{RESUMO:}

O tema em epígrafe levanta uma questão relevante aos debates atuais acerca das recentes preocupações do homem, tendo em vista sua relação com a natureza. Da análise de tal relação parte o eixo de discussão que enfatiza o contexto de impacto socioambiental e sua previsão quanto às fases de realização e operação de empreendimentos hidroelétricos. O direcionamento da discussão trata, dentre outras circunstâncias, do entorno da barragem hidrelétrica Xingó passível de impactos sejam ambientais ou sociais, como o recorte espacial estudado, município de Porto da Folha/SE, à margem do rio São Francisco. Além disso, o presente trabalho questiona a área de influência considerada pelo Estudo de Impacto Ambiental / Relatório de Impacto Ambiental (EIA/Rima) de Xingó, o que fez denotar alguns aspectos que caracterizam faltas de ações de governo, em termos de políticas públicas, assim como políticas de mitigação de impactos.

\section{PALAVRAS-CHAVE:}

impacto socioambiental; área de influência no EIA/Rima; políticas públicas; previsão de impactos; relação homem-natureza.

\section{SUMMARY:}

ENVIRONMENTAL IMPACTS ON THE RIVER SAN FRANCISCO: RESULT OF LACK OF CONSIDERATION OF THE INFLUENCE AREA REAI. The above-mentioned issue raises a question relevant to current debates about recent concerns of man, given its relationship with nature. The examination of such part of the axis of discussion that emphasizes the context of environmental impact and its forecast for future phases of implementation and operation of hydroelectric projects. The direction of the discussion about, among other circumstances surrounding the hydroelectric dam Xingó likely to impact whether environmental or social as the spatial area studied, the municipality of Porto da Folha-SE, the river San Francisco. Moreover, this question made the area of influence considered by the Environmental Impact Assessment / Environmental Impact Report (EIA / RIMA) Xingó, which he did denote some aspects that characterize lack of government actions in terms of public policy, well as policies to mitigate impacts.

\section{KEYWORDS:}

environmental impact, area of influence in the EIA/Rima, public policy, forecast impacts; relationship man nature.

\section{Apresentação}

No mundo contemporâneo tem-se ouvido falar muito em preservação ambiental, mas não se vê muitos esforços concretos se realizando nesse sentido por parte dos setores público e privado. O tema do presente estudo aborda essa questão, de forma que traz uma crítica a respeito da ação do homem sobre a natureza.

Este trabalho procura deixar explícito o sentido de impacto socioambiental no bojo da geografia e como se alastrou na área de estudo, à margem do rio São Francisco. Assegura a 
preeminência da caracterização de Porto da Folha/ SE como margem desse rio, apesar dos impactos terem desconfigurado a plenitude desse espaço. Além disso, mostra que diversos fatores no ciclo de cheias naturais configuraram a circunscrição da sede municipal portofolhense como enclave do sertão sergipano.

Por fim, faz uma breve análise sobre alguns pontos do Estudo Prévio de Impacto Ambiental / Relatório de Impacto Ambiental da Usina Hidroelétrica de Xingó (a última que interfere o leito do rio São Francisco, sentido jusante), localizada entre os Estados de Alagoas e Sergipe, aferindo-os a outros pontos da Lei de Política Nacional de Meio Ambiente. Depois, faz uma breve avaliação da ação do Estado acerca de sua responsabilidade quanto aos impactos que se alastraram na região.

\section{Método}

A metodologia científica apresenta dois momentos, o levantamento bibliográfico e o trabalho de campo.

O método utilizado no desenvolvimento da pesquisa ocorreu conforme segue: foi feito levantamento bibliográfico que procedeu à fundamentação teórico-metodológica; dados como a produção de arroz desde 1952 até 2007, importantes para o contexto do estudo, foram levantados no trabalho de campo e tabulados, mas momentos que sucedem o ano de 1990 não foram representados porque a partir desse período se quebrou o ciclo de produção que havia na área de estudo; fez-se o emprego de recursos cartográficos como gráfico, tabela, mapa, para colaborar com o contexto do presente feito.

Além disso, o Estudo de Impacto Ambiental / Relatório de Impacto Ambiental (EIA/ Rima) da Usina Hidroelétrica Xingó (UHE), fundamental para o desenvolvimento do trabalho, foi analisado com cautela.

A partir dessa análise, pontos das resoluções Conama 01/86 e 06/87 foram aferidos com outros do EIA/Rima no intuito de esclarecer melhor a questão em epígrafe.

\section{O conceito de impacto socioambiental e a caracterização do lugar como margem do rio São Francisco}

Para SANTOS (2008, p. 89), "impacto ambiental é o desequilíbrio conseqüente de um dano que se vale de agentes diversos capazes de interromper a harmonia existente na relação entre ser vivo e natureza por causa da ação do homem sobre o meio ambiente".

Segundo a Resolução do Conselho Nacional do Meio Ambiente (Conama) - Instituto Brasileiro do Meio Ambiente e dos Recursos Naturais Renováveis (Ibama), no 1/86, artigo 10, impacto ambiental é:

Qualquer alteração das propriedades físicas, químicas ou biológicas do meio ambiente, causada por qualquer forma de matéria ou energia resultante das atividades humanas, que direta ou indiretamente afetem:

I - a saúde, a segurança e o bem-estar da população;

II - as atividades sociais e econômicas;

III - as condições estéticas e sanitárias do meio ambiente;

IV - a qualidade dos recursos ambientais.

De acordo com ALMEIDA e RIGOLIN (2002, p. 159), "podemos dizer que os impactos ambientais são uma espécie de 'choque' que rompe o equilíbrio ecológico". Nesse sentido, pode-se dizer que há uma harmonia nas relações entre os seres vivos e o meio ambiente, o chamado equilíbrio ecológico. Quando esse é quebrado por intermédio da ação humana, se confirma o impacto ambiental. O qual, a princípio, atinge o meio físico e, a partir desse, o problema pode acarretar outras consequências possíveis de atingir a sociedade.

Foi nessa concepção que os impactos passaram a ser observados à margem do rio São Francisco. Atingiram tanto o espaço natural quanto a sociedade, de forma que esta foi afetada em consequência dos impactos que se alastraram, a princípio, na natureza. Desse modo, considerando a maneira como o problema 
ocorreu, vem assegurar que referidos impactos são socioambientais. Ou seja, o fato não pode ser percebido como impacto ambiental apenas, pois além de atingir o meio ambiente causou consequências ao próprio homem.

Em razão disso, é importante entender o que é meio ambiente porque para Trepl (2006) é ambíguo, não é visto por si só como a real existência de meio ambiente.

Segundo SÁNCHEZ (2006, p. 18):

O conceito de 'ambiente', no campo de planejamento e gestão ambiental, é amplo, multifacetado e maleável. Amplo porque pode incluir tanto a natureza quanto a sociedade. Multifacetado porque pode ser apreendido por diferentes perspectivas. Maleável porque, ao ser amplo e multifacetado, pode ser reduzido ou ampliado de acordo com necessidades do analista ou interesses dos envolvidos.

Desse modo, pode-se afirmar que meio ambiente é tudo o que envolve os seres vivos, de forma que sua abrangência se distingue da natureza e do espaço social porque os elementos destes promovem existência de elos entre os seres vivos no referido meio. No entanto, nesse sentido, seu conceito não pode ultrapassar o de natureza, porque esta é o conjunto de todos os seres que constituem o Universo e, neste ponto de vista, o referido ambiente pertence a esse conjunto. Como seu conceito é amplo por abarcar tanto o que se refere ao meio social quanto ao espaço natural, dessa forma, não deixa de ser passível das consequências causadas tanto pela sociedade como pela natureza.

Tais consequências, como a extinção do ciclo natural de enchentes do rio São Francisco em Porto da Folha/SE, desencadearam vários impactos socioambientais. Noutras palavras, a extinção de tal ciclo acarretou impactos na natureza que, por sua vez, engendraram outros, afetando a comunidade local. Exemplo disso foi a supressão da exuberante floresta tropical hidrófila de várzea e o rebaixamento do lençol freático que existiram no lugar enquanto durou a vazão natural do rio, e devido à falta dessa vazão aconteceu a extinção do ciclo da cultura arrozeira, do qual a comunidade dependia para sobreviver.

Observa-se que o fato passou a ser notório sobre o lugar por volta do final do Século XX, a partir de meados da década de 1980 culminando em meados da década de 1990, de forma que atingiu, significativamente, a várzea denominada Ilha do Ouro, a Nordeste da sede municipal. Da análise do mapa (figura 01), observa-se que Porto da Folha está a Noroeste de Sergipe, a $180 \mathrm{~km}$ da capital, Aracaju, e a $80 \mathrm{~km}$ da barragem Xingó.

Por motivos como esse, por volta da segunda metade do século $X X$, ambientalistas brasileiros, seguidores de diversos cientistas mundiais voltados para a defesa do meio ambiente e da sociedade, surgiram preocupados com o futuro do próprio povo e desse meio.

Essa preocupação pode ser observada quando AB'SABER (2006, p. 31), cita:

Nesse sentido, prever impactos é um ato de tomada de precauções para garantir a harmonia e compatibilizar funções no interior do espaço total no futuro. É também, por extensão um ato de bom senso, em que se procura harmonizar o desenvolvimento com uma correta postura de proteção ambiental e ecológica.

Nesse sentido, o presente estudo enfoca o tema em epígrafe, principalmente, voltando às atenções para o rio São Francisco porque sofreu expressivas alterações no seu volume devido aos impactos engendrados pela ação humana (executora do empreendimento hidroelétrico Xingó). Entre outras circunstâncias, merece destaque a significativa diminuição de vazão que o rio sofreu após o paredão da barragem até a foz, pois isso resultou na extinção do ciclo das cheias naturais.

A relevância dada ao São Francisco, entre outras motivos, deve-se ao fato de a comunidade ribeirinha ter seu desenvolvimento, ao longo do ciclo do arroz, em virtude de sua relação com o rio. 
Por esta razão, estudar o recorte espacial em questão foi necessário porque o leito do rio, a partir da década de 1970 até o final do século $X X$, foi marcado por um período de construção de várias barragens hidrelétricas.

\section{PORTO DA FOLHA FM RELAÇÃO AO ESTADO DE SERGIPE \\ E A VÁRZEA ILHA DO OURO NO MUNICÍPIO}

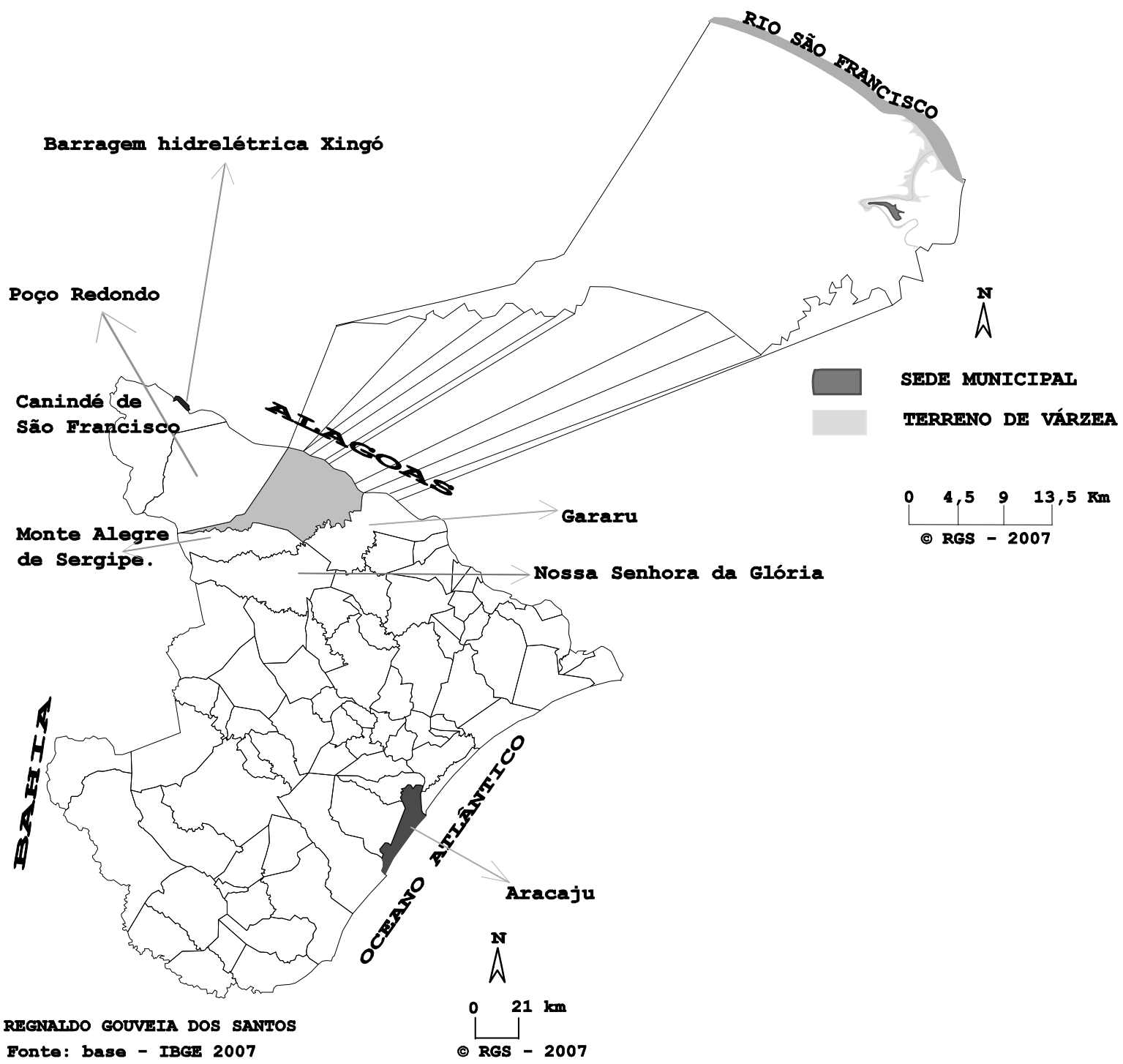

Figura 01. Área de estudo. Fonte: Impactos socioambientais à margem do rio São Francisco: um estudo de caso, 2008. 
Por isso, foi levantada a hipótese de que os referidos impactos ocorreram devido às intervenções do empreendimento hidroelétrico Xingó sobre o controle da vazão do rio. Apesar da existência das barragens Sobradinho, Complexo de Paulo Afonso I, II, III e IV, Luiz Gonzaga (antiga Itaparica) e Moxotó no leito do São Francisco, seus possíveis impactos não pesam tanto quanto os engendrados pela Xingó sobre o lugar em virtude de sua proximidade.

A instalação dessas várias usinas hidrelétricas, através de seus reservatórios, interveio sobre a vazão natural, mas não tanto quanto o último reservatório dos oito acima citados por ser determinante dos impactos socioambientais desencadeados em Porto da Folha/SE.

A caracterização da sede municipal portofolhense como margem do rio São Francisco perdurou, naturalmente, desde o princípio de sua fundação até enquanto existiu o ciclo de cheias naturais do rio. O mapa (figura 01 ) contribui com o esclarecimento do episódio que era caracterizado através da extensa planície fluvial do lugar, haja vista ao caudal sãofranciscano que banhava a maior parte do pequeno planalto onde se localiza a sede municipal.

Ainda que, atualmente, estorvem o sentido pleno da sede municipal estar à margem do São Francisco devido à extinção de seu ciclo de cheias naturais, é possível afirmar que o referido local não deixa de ser margem do rio. Referentemente a isso, as cheias fluviais a qualquer momento podem retrogradar ao aspecto natural, ressurgindo seja por falha do controle de vazão nas barragens ou por reação da natureza. Hoje em dia, nessa concepção, notícias têm sido veiculadas na imprensa escrita e falada de acordo com catástrofes ambientais brasileiras.

Para melhor cristalizar a concepção de impacto socioambiental que, neste caso, tem seu sentido pleno na consequência que atinge o homem, ser social, conforme o assunto acima foi abordado é relevante discorrer sobre a relação do povo do lugar com a natureza. Ao analisar a

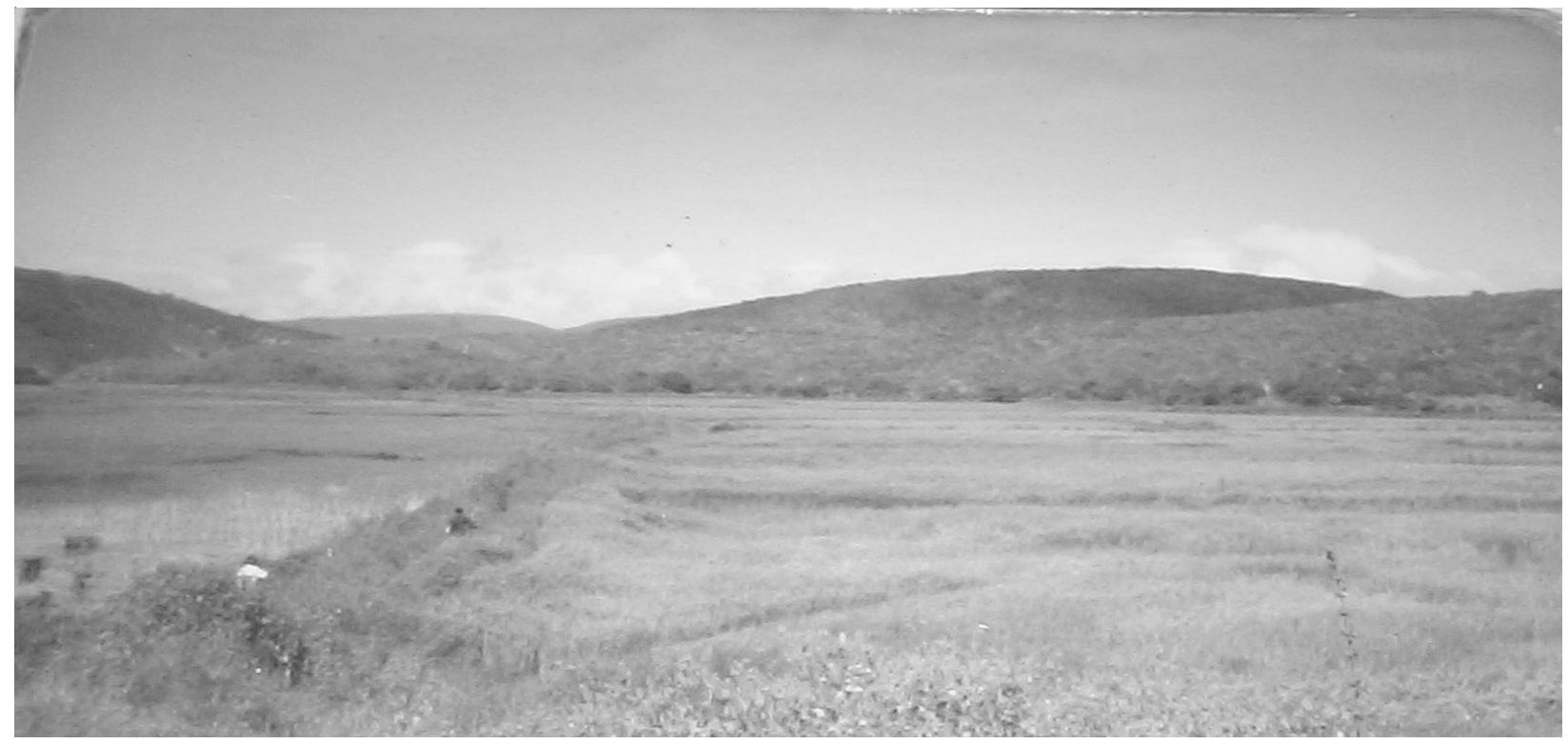

Figura 02. Várzea Ilha do Ouro. Fonte: Impactos socioambientais à margem do rio São Francisco: um estudo de caso, 2008. 
figura 02 é possível observar o resultado da relação do ribeirinho do Baixo São Francisco Sergipano com a natureza do lugar quando do ciclo de cheias naturais que resultava no ciclo do arroz. Resultado este que se encontra estampado em primeiro plano da figura, a extensa lavoura do cereal. Vê-se que não há nenhum tipo de tecnologia presente no cultivo do arroz. Além disso, a água acumulada na várzea, visível no lado esquerdo da figura, ratifica uma das técnicas do sertanejo portofolhense que se valia apenas de sua força braçal no manejo desta cultura de subsistência.

Tabela 2 - Porto da Folha/SE: estabelecimentos de acordo com a força de trabalho utilizada - Trabalhos agrários

\begin{tabular}{lllll}
\hline \hline Município & Humana & Animal & Mecánica & Animal e mecânica \\
Porto da Folha & 1369 & 10 & - & - \\
& & & & \\
\hline
\end{tabular}

Tabela 01. Fonte: Impactos socioambientais à margem do rio São Francisco: um estudo de caso, 2008.

Já em segundo plano da figura 02 é perceptível a exuberante floresta tropical hidrófila de várzea, embora a cor não contribua com tanta notabilidade devido à falta de qualidade do instrumento utilizado com tal finalidade, pois a foto data da década de 1970.

De acordo com a tabela 01 ratifica-se a assertiva de que os ribeirinhos portofolhenses não se utilizavam de tecnologia no cultivo da lavoura arrozeira. Referentemente a isso, conforme o IBGE (1960), no lugar, as propriedades na década de 1960 não utilizavam a força mecânica nem o conjunto dessa força com a animal nos trabalhos agrários.

Essa cultura era de subsistência para aquela comunidade porque a mesma sobrevivia do cultivo do cereal que resultava do ciclo das cheias naturais do rio São Francisco. Por essa razão e por causa da grande população de peixe presente nas pequenas lagoas da extensa planície fluvial, segundo SANTOS (2008) os ribeirinhos afirmaram em entrevista que o ciclo das cheias naturais foi tempo de fartura.

Em contrapartida, no gráfico 01 é possível observar que a partir das atividades da Usina Hidroelétrica Xingó o ciclo da cultura arrozeira no lugar passa a ser extinto, de forma que a produção do cereal, primeiramente, sofre queda brusca até desaparecer totalmente. Isso foi notável a partir de 1987 quando as obras da barragem de Xingó tiveram início.

De acordo com a pesquisa, apesar de constatados alguns anos de produção de arroz após 1990 até o presente momento, conforme IBGE (2009), mas que foram pouquíssimos e que se deram a partir de enchentes artificiais como em apenas 1991, 1992, 1994 e 1997, o ciclo não se restabeleceu.

Por fim, é importante frisar que só há impacto socioambiental se uma comunidade ou sociedade sofrer uma consequência resultante de outra causada pela ação humana ou natural sobre o meio ambiente. 


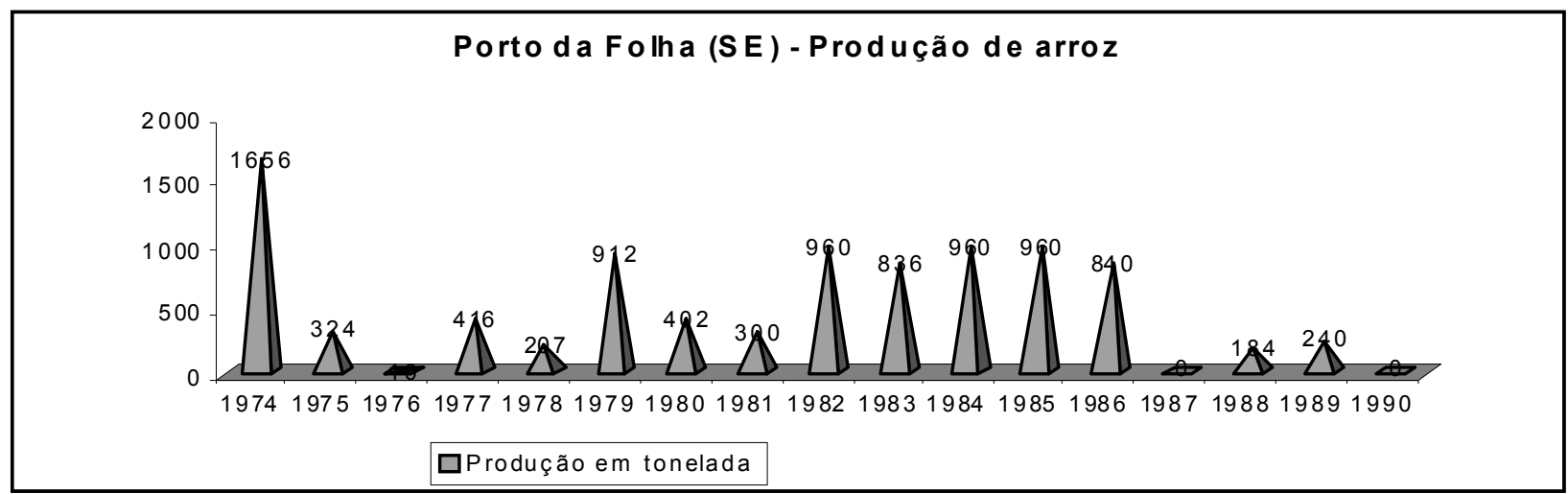

Gráfico 01. Fonte: Impactos socioambientais à margem do rio São Francisco: um estudo de caso, 2008.

\section{Um aspecto da natureza do lugar e sua distinção em relação à caatinga do sertão}

De acordo com REBOUÇAS (1999, p. 09), "A umidade do solo é o suporte fundamental que garante o desenvolvimento de uma exuberante biomassa vegetal natural ou cultivada nas faixas úmidas intertropicais. Como ela é consumida onde ocorrem as chuvas, a umidade do solo constitui reservas de água ditas localizadas". Como o ciclo de cheias naturais do rio São Francisco atingia todo o vale da extensa planície fluvial do lugar, a várzea permanecia inundada por cerca de seis meses. Esse fator natural, certamente, não resultava diretamente por conta da chuva devido ao clima semiárido da região, mas surtia o mesmo efeito conforme o autor acima observou. A biomassa vegetal, floresta tropical hidrófila de várzea, era preservada dessa forma. Sua paisagem exuberante era observada desde os sopés das vertentes até determinada cota altimétrica do vale em que está localizada a várzea Ilha do Ouro. Já pontos de afloramento de água que existiram na circunscrição dessa área, quando das cheias naturais do rio São Francisco, restringiam-se à existência desses fatores naturais.

Essas características naturais tão diferentes da caatinga do Sertão de Sergipe formavam uma mancha verde exuberante desde a beira do rio São Francisco, seguindo as bordas da extensa planície fluvial, até as adjacências da sede municipal portofolhense. É possível perceber que essas características são fatores fundamentais observados "para designar manchas de ecossistemas típicos de outras províncias, porém, encravadas no interior de um domínio de natureza totalmente diferente[...]" (AB'SÁBER, 2003, p. 145). Isso permite afirmar que essa área era um enclave.

\section{Uma breve análise sobre o EIA/Rima e a ação do Estado quanto ao problema contextualizado}

Ao questionar a área de influência do empreendimento hidroelétrico Xingó, é importante salientar que o EIA/Rima deve, na forma da lei, definir a respectiva área de influência como direta ou indireta conforme os impactos que Ihes afeta. Da mesma forma, deve considerar, em todos os casos, a bacia hidrográfica na qual está inserida, pois de acordo com o Conselho Nacional do Meio Ambiente - IBAMA (1986), Resolução CONAMA n० 01/86, artigo 50:

O estudo de impacto ambiental, além de atender à legislação, em especial os princípios e objetivos expressos na Lei de Política Nacional do Meio Ambiente, obedecerá às seguintes diretrizes gerais: 
III - Definir os limites da área geográfica a ser direta ou indiretamente afetada pelos impactos, denominada área de influência do projeto, considerando, em todos os casos, a bacia hidrográfica na qual se localiza;

No entanto, o EIA/Rima de Xingó não atendeu a esse critério, no sentido de que considerou apenas cinco municípios como as duas áreas de influência do empreendimento, embora existam muitos outros tanto alagoanos quanto sergipanos à margem do rio que foram igualmente afetados pelos impactos. Fato que chama a atenção é a distância que o curso do rio percorre desde o paredão da barragem até a foz, atingindo mais de cento e setenta quilômetros. Nem por isso, municípios que se encontram à margem, a menos de cem quilômetros da interferência fluvial não foram inseridos em determinadas áreas.

Haja vista o que consta na Resolução Conama 01/86, conforme acima citado, sobre a bacia hidrográfica, referentemente ao EIA/Rima, é importante frisar o que pode ser entendido por bacia hidrográfica. De acordo com a ciência geográfica, uma bacia hidrográfica considera-se segundo seu relevo, pelo menos, o espaço em que se encontra o rio principal, seus tributários, os divisores de água que declinam em direção de um dos tributários ou do rio principal. Nesse contexto, a área de influência real levantada no presente estudo é entendida como todo o espaço natural da bacia hidrográfica, mais o espaço geográfico em que o homem é capaz de se relacionar com a natureza. Desse modo, acreditase que a bacia hidrográfica que deve ser considerada em todos os casos segundo a Lei não seja entendida como o mínimo espaço levantado pelo EIA/Rima de Xingó ao delimitar a Área de Influência desse empreendimento.

Assim, como as águas do São Francisco, naturalmente, têm rumo a sua foz e por Xingó ser a última interferência artificial da vazão, neste caso, precisa que a área em questão seja considerada, pelo menos, a partir dessa barragem até a foz do rio.

Por todos esses aspectos, é importante frisar que, do ponto de vista legal, é possível observar o descumprimento do EIA/Rima de Xingó em relação à Lei de Política Nacional de Meio Ambiente, pois a usina hidroelétrica entrou em atividade em 1994. Referentemente a isso, a Licença de Operação deve ser emitida antes de a barragem ser fechada, o que não foi cumprido no caso do empreendimento de Xingó, pois da análise da pesquisa, tal licença foi confirmada em 1999.

Ratificam-se as assertivas acima de acordo com o artigo $4^{\circ}$ da Resolução CONAMA no 06/87 (1987, grifo nosso):

Art. 40 Na hipótese dos empreendimentos de aproveitamento hidroelétrico, respeitadas as peculiaridades de cada caso, a Licença Prévia (LP) deverá ser requerida no início do estudo de viabilidade da Usina; a Licença de Instalação (LI) deverá ser obtida antes da realização da Licitação para construção do empreendimento e a Licença de Operação (LO) deverá ser obtida antes do fechamento da barragem.

Por qualquer motivo que no EIA/Rima se encontre a intenção de se eximir do erro contextualizado e se isso for aceito, é preciso que o referido estudo de impacto ambiental passe a ser rediscutido no circuito acadêmico como aqui está sendo feito, haja vista sua importância na gestão de política ambiental. Já a área de influência apontada no EIA/Rima da hidrelétrica Xingó é inaceitável em qualquer hipótese, pois o espaço total não foi considerado.

O Estado, por meio de seus setores, tem conhecimento do problema contextualizado, tanto que, segundo SANTOS (2008), representantes das instituições estatais, em entrevistas, têm demonstrado saber sobre a situação. Notou-se que projetos foram instalados com o intuito de mitigar os referidos impactos, mas muitos não têm apresentado eficiência, tampouco foram efetivos. De acordo com SANTOS (2008), um dos representantes se referiu ao fato de que após a operação da hidrelétrica Xingó a empreendedora se comprometeria em liberar vazão suficiente para que ocorressem enchentes artificiais próximas do normal, de forma que não predominasse tão baixa quanto tem ocorrido. É possível afirmar que essa ação é pérfida, levando-se em conta a baixa vazão 
que o rio enfrenta a partir do paredão de Xingó. Além disso, há projetos de assentamentos agrícolas nas proximidades do São Francisco que não possuem uma rede de irrigação adequada sequer para o desenvolvimento de agricultura de subsistência.

$O$ que instiga o presente estudo referente à ação do Estado é o fato de este ter implementado um conjunto de ações capaz de vir ao encontro da mitigação de parte dos impactos que se alastraram em todo o Baixo curso do rio São Francisco. No entanto, isso se concentrou de forma nítida na Área de Influência considerada pelo EIA/Rima de Xingó. Entre as ações de governo implementadas em municípios dessa área, merecem destaque os projetos hidroagrícolas, assim como o Califórnia e o Jacaré - Curituba que contribuíram com o desenvolvimento dos dois municípios sergipanos mais próximos da barragem.

Além de tudo, o município de Porto da Folha/SE que foi atingido diretamente pelos impactos socioambientais não foi contemplado com tais políticas. Cabe frisar que esse município já se destacou em terceiro lugar na produção de arroz de todo o Estado de Sergipe.

Tudo isso ratifica que a falta de implementação de políticas necessárias por causa dos impactos ali desencadeados tem sido um descaso por parte do Estado, Instituição que tem poder para agir neste caso.

\section{Conclusão}

Com essa abordagem, espera-se que o episódio ocorrido na margem do rio São Francisco seja denotado, além disso, que as autoridades competentes tomem providências cabíveis sobre o que foi revelado neste estudo. Assim, certamente, ocorrerá relevante contribuição para a região e um avanço, sobre a interpretação de área de influência de grandes empreendimentos como os hidroelétricos, para a Geografia.

Observou-se que o Estudo de Impacto Ambiental / Relatório de Impacto Ambiental (EIA/ Rima) merece ser discutido quanto à importância e consideração legal.
Quanto à área de influência de grandes empreendimentos como os hidroelétricos, o presente estudo revelou que tal área deve ser levada em consideração conforme aqui foi mostrado segundo a ciência geográfica, mas não considerar apenas o que o empreendedor observa. Nesse sentido, se considerar apenas as observações de poucos que fazem parte da elaboração do EIA, se acredita que muitos impactos podem passar despercebidos em tal estudo ou sua omissão pode confirmar-se. Um exemplo é o que ocorreu na área do presente estudo.

A área de influência de empreendimentos como a que está em discussão precisa ser considerada como a abrangência da bacia hidrográfica atingida. Ou seja, tem de considerar o espaço natural e o espaço geográfico (espaço natural alterado pela ação humana), além da relação direta ou indireta que há entre o homem e a natureza, principalmente, concernente à comunidade do lugar atingido. Nesse sentido, observou-se que toda a margem do rio São Francisco, desde o paredão da barragem Xingó até a foz do rio, foi afetada pelos impactos direta e indiretamente, merecendo ser, pois, considerada como área de influência real.

Apesar da transformação espacial que o lugar sofreu devido aos impactos, os aspectos físicos não o descaracterizaram como margem do rio São Francisco.

Foi possível observar que há uma diferença entre impacto ambiental e impacto socioambiental. No primeiro caso o impacto atinge o meio ambiente e no segundo, o resultado do primeiro engendra consequências numa comunidade ou sociedade. No entanto, o impacto socioambiental não deixa de ser um conjunto do impacto ambiental mais o impacto social. Desse modo, só haverá impacto socioambiental se uma comunidade ou sociedade sofrer consequências em razão de impacto ambiental.

Enfim, a ausência de ações de governo no lugar, em relação à extrema necessidade de aplicação de políticas de mitigação dos impactos que se alastraram, ratifica algo que pode ser entendido como omissão do Estado. 


\section{Referências Bibliográficas}

AB'SABER, Aziz Nacib. Os domínios de natureza no Brasil: potencialidades paisagísticas. São Paulo: Ateliê Editorial, 2003. 160 p.

AB'SABER, Aziz Nacib \& PLANTENBERG, Clarita Muller (org). Previsão de impactos. $2^{a}$ edição. São Paulo: Edusp, 2006. 573 p.

ALMEIDA, Lúcia M. Alves de; RIGOLIN, Tércio B. A Questão ambiental: natureza, sociedade e tecnologia. In: - Geografia: série - novo ensino médio. São Paulo: Editora Atica, 2002. p. 07-186.

BRASIL. Conselho Nacional do Meio Ambiente Instituto Brasileiro do Meio Ambiente e dos Recursos Naturais Renováveis (CONAMA/IBAMA). Para efeito desta Resolução considera-se impacto ambiental... Resolução Conama, no 01, 23 de janeiro de 1986. Resoluções, Brasília, fevereiro de 1986.

Dispõe sobre o licenciamento ambiental de obras do setor de geração de energia elétrica. Resolução Conama, no 6, 16 de setembro de 1987. Resoluções, Brasília, outubro de 1987.

. Usina hidrelétrica de Xingó: Estudo de Impacto Ambiental - EIA. Tomo I - memorial descritivo do empreendimento. Rio de Janeiro: [s.n.]. 1993. 113 p.

. Usina hidrelétrica de Xingó: Estudo de Impacto Ambiental - EIA. Tomo II - diagnóstico ambiental, volume 01 - meio físico. Rio de Janeiro: [s.n.]. 1993. 282 p.

Usina hidrelétrica de Xingó: Estudo de Impacto Ambiental - EIA. Tomo II - diagnóstico ambiental, volume 02 - meio biótico. Rio de Janeiro: [s.n.]. 1993. 201 p.

Usina hidrelétrica de Xingó: Estudo de Impacto Ambiental - EIA. Tomo II - diagnóstico ambiental, volume 03 - meio antrópico. Rio de Janeiro: [s.n.]. 1993. 208 p.

- Usina hidrelétrica de Xingó: Estudo de Impacto Ambiental - EIA. Tomo III - prognóstico ambiental. Rio de Janeiro: [s.n.]. 1993. 86 p.
BRASIL. Conselho Nacional do Meio Ambiente Instituto Brasileiro do Meio Ambiente e dos Recursos Naturais Renováveis (CONAMA/IBAMA). Usina hidrelétrica de Xingó: Estudo de Impacto Ambiental - EIA. Tomo IV - programas ambientais. Rio de Janeiro: [s.n.]. 1993. 64 p.

Relatório de Impacto Ambiental - RIMA: Usina Hidrelétrica de Xingó - UHE XINGÓ. Rio de Janeiro, [s.n.], [1993 ou 1994]. 108 p.

. Aspectos gerais do empreendimento. In: . Usina hidrelétrica de Xingó. Projeto Básico Ambiental - PBA: programa de manejo e conservação da fauna aquática. Rio de Janeiro: [s.n.]. 1994. 1-10 p.

Projeto de manejo e conservação da fauna aquática. In: . Usina hidrelétrica de Xingó. Projeto Básico Ambiental - PBA: projeto de manejo e conservação da fauna aquática. Rio de Janeiro: [s.n.]. 1994. 11-62 p.

INSTITUTO BRASILEIRO DE GEOGRAFIA E ESTATÍSTICA. Censos econômicos: agrícola, industrial, comercial e dos serviços recenseamento geral do Brasil (10 de setembro de 1940), série regional - parte XI - Sergipe. Rio de Janeiro: IBGE, 1952.

. Produção agrícola: discriminada por município - 1953 - Sergipe. Rio de Janeiro: IBGE, 1954.

Censo agrícola de 1960: VII recenseamento geral do Brasil - série regional Alagoas - Sergipe. Volume II - tomo VII - $1^{\text {a }}$ Parte. Rio de Janeiro: IBGE, 1960.

- Produção agrícola: discriminada por município - 1974-1990 - Sergipe. Rio de Janeiro: IBGE, (17 vols.).

Censo agropecuário de 1980: IX recenseamento geral do Brasil - Sergipe. Volume II - tomo III - no 14. Rio de Janeiro: IBGE, 1983.

. Produção Agrícola Municipal - PAM, SIDRA. Disponível em: < http:// www.ibge.gov.br>. Acessado em: 04 de abril de 2009. 
REBOUÇAS, Aldo da Cunha. Água doce no mundo e no Brasil. In: REBOUÇAS, Aldo da Cunha; BRAGA, Benedito; TUNDISI, José Galízia (orgs.). Águas doces no Brasil: capital ecológico, uso e conservação. São Paulo: Escrituras, 1999. p. 1-38.

SÁNCHEZ, Luis E. Conceitos e Definições. In: - Avaliação de Impacto Ambiental: conceitos e métodos. São Paulo: Oficina de Textos, 2006. Capítulo 01. p. 17-43.

SANTOS, Regnaldo Gouveia dos. Impactos socioambientais à margem do rio São Francisco: um estudo de caso. 2008. $193 \mathrm{f}$. Dissertação de Mestrado - DPGEO/FFLCH-USP, São Paulo, 2008.

Trabalho enviado em outubro de 2009

Trabalho aceito em dezembro de 2009 